\title{
The effect of time on the results of children's spine examinations
}

\author{
M. Takács ${ }^{1}$, E. Rudner ${ }^{1}$ \& R. M. Kiss ${ }^{2}$ \\ ${ }^{1}$ Department of Orthopaedics MÁV Hospital, Szolnok, Hungary \\ ${ }^{2}$ Department of Structures, \\ Budapest University of Technology and Economics, Hungary
}

\begin{abstract}
With the ultrasound based motion analyzing system it is possible to measure the shape of the spine not only of adults but of children too. Ultrasound based spine measurements play an important role in diagnosing spine deformities in children (bad posture, flat back, scoliosis), as well as after diagnosis, during conservative follow-up. Previous research has already justified the accuracy and reliability of the ultrasound-based analysis method. However, the question of whether the short length of time between the two tests had an effect on the results was not examined and answered by previous research. The aim of our study was to clarify whether the shape of the spine changes significantly during the 15 minute-long examination of healthy children and children with various spine deformities. We measured children aged 8 to 11 , of whom 115 were healthy (52 boys, 63 girls, average age: $8.7 \pm 1,2$ years, average weight: $35.8 \pm 9,7 \mathrm{~kg}$, average height: $138.8 \pm 9,05 \mathrm{~cm}), 56$ had bad posture (21 boys, 35 girls, average age: $8.4 \pm 1,26$ years, average weight: $30.6 \pm 7,67 \mathrm{~kg}$, average height: $137.0 \pm 9,18$ $\mathrm{cm}$ ), 6 had flat backs ( 3 boys, 3 girls, average age: $8.3 \pm 1,21$ years, average weight: $31.2 \pm 6,43 \mathrm{~kg}$, average height: $138.2 \pm 7,88 \mathrm{~cm}$ ) and 20 had scoliosis (10 boys, 10 girls, average age: $9.3 \pm 1,13$ years, average weight: $32.9 \pm 4,95 \mathrm{~kg}$, average height: $134.4 \pm 6,76 \mathrm{~cm}$ ). At first we described the shape of the spine in a straight posture using the Zebris ultrasound motion analysis system, then we repeated the procedure after 15 minutes. When we compared the results it turned out that the differences were significantly smaller than the standard deviations (0.1-2.7 at kyphosis, $0.3-7.4$ at lordosis, $0.1-1.1$ at sagittal inclination, and finally 0.1-1.0 at frontal inclination). The correlation was strong at kyphosis and lordosis (0.77-0.98), however, it was low at frontal and sagittal inclination (0.18-
\end{abstract}


0.54). So the time lapse (15 minutes) between the measurements did not affect the results at lordosis and khyphosis. At inclination, however, it is essential to pay extra attention to the postures.

Keywords: bad posture, spine, spine curvature, schoolchildren, ultrasoundbased system, Zebris, posture.

\section{Introduction}

Medical literature describes children's low back pain and back pain as multifactorial problems and it is also states that further research is needed to reveal their medical background. The influencing factors are complex and in many cases their effects on each other are not clarified. Out of these effects we have to emphasize the body mass index, the mobility and flexibility of muscles and joints, muscular strength, low endurance and asymmetric development of trunk flexors and extensors and the effects of the disturbance of muscle balance [1]. Also sports, furniture in schools, heavy school backpacks, psychological factors and smoking - although in different ways - play an important role in children's spine development [2, 3,]. In most cases, children's back pain experiences are mild and do not affect their daily life $[1,4,5]$. Literary data prove that child and puberty back pain significantly increases the probability of puberty and adulthood back pain and other structural spine problems [1, 6, 7]. Besides prevention, it is necessary to lay emphasis on the screening test and follow-up of childhood spine deformities because many times they are symptomless. When they are discovered late the efficiency of the cure decreases and the probability of different spine problems during adulthood increases. The main cause of spine problems without structural deformities in adulthood is simple bad posture in childhood and puberty. One of the causes of simple bad posture is that in children between the ages of 6 to 10 the muscular development required often lags behind the quick height increase. Diagnosis at an early stage followed by appropriate correction is the first step towards prevention. It can be stated that the survey of children's postures and conditions is essential for the prevention of structural and non-structural spine deformities. The application of screening tests makes it possible to establish an exact diagnosis and to start a conservative therapy at the earliest moment. Beside the well-known diagnostic methods, those measurements are also necessary to be used which can be used in short intervals and allow continuous control of the effects of treatment. In order to measure the state of the children it is necessary to use devices that do not burden their organism with $\mathrm{X}$-ray radiation and produce reliable results [8, 9]. The examination method, just like the causes of the clinical picture, has to be complex. Traditional physical orthopaedic examination, definition of the spine's shape in different postures and the measurement of muscle activity by skinsurface EMG during motion are parts of the whole examination method $[8,10$, 11]. In our research we lay emphasis on the examination of the shape of the spine. The simplest way to define the shape of the spine is to make a full X-ray image in a standing and natural position. From the photographs, lumbar lordosis, thoracal kyphosis and the scoliosis of the spine curvature can be defined. On the 
images the position of vertebrae can also be identified [12]. The major drawback of this test is that the X-ray load is high so it is proposed to be repeated only annually in spine deformities, while with posture abnormalities it is not suggested for follow-up. Ultrasound based systems are used in a wide range at adults, but we may find some examples in children's tests too $[1,12,13]$. The accuracy and reliability of the examination method can be controlled by comparing it to the results of other measuring devices (e.g. X-ray images) by test-retest examination, but the effect of test time is also important [1,13-15]. In children, the effect of time on measurement results is unambiguous, particularly in children with weak musculature (e.g. bad posture). In adults it can be neglected because adults' musculature and ability to concentrate enable them to keep the required position (habitual straight position) for a longer time. When the test is performed by Zebris ultrasound-based measurement it is necessary to specify the reference points of comparison, and then to define the shape of the spine. These tests take 10-12 minutes. The aim of the study was to clarify whether the time of the examination influences the results of measurements in different childhood spine deformities. 8 to 11 year old healthy, bad postured, flat backed (dorsum planum) children and children with scoliosis participated in the study. We defined the shape of the spine in straight position by the Zebris ultrasound-based motion analysis system; then, 15 minutes later, we repeated the measurements. The tests were performed by the same examiners on both occasions.

\section{Material and method}

\subsection{Subjects}

The subjects of our research were children from two primary schools in Szolnok. One class was chosen from each grade from the first to the fourth grade. The classes were music and art specific. We did not choose sports classes. Parents received the necessary information both orally and in a written form before they filled in their consent. At the end, 195 children were measured, including 84 boys and 111 girls. Based on the results of the previous orthopaedic tests, the children were divided into four groups.

The first group contained 115 healthy children, including 52 boys and 63 girls, with an average age of $8.7 \pm 1,2$ years, an average weight of $35.8 \pm 9,7 \mathrm{~kg}$ and an average height of $138.8 \pm 9,05 \mathrm{~cm}$. 56 children with bad posture were put into the second group ( 21 boys, 35 girls) where the average age was $8.4 \pm 1,26$ years, the average weight $30,6 \pm 7,67 \mathrm{~kg}$ and the average height $137,0 \pm 9,18 \mathrm{~cm}$. 6 children had flat back ( 3 boys, 3 girls, average age: $8.3 \pm 1,21$ years, average weight: $31.2 \pm 6,43 \mathrm{~kg}$, average height: $138.2 \pm 7,88 \mathrm{~cm}$ ) while the last 20 had scoliosis (10 boys, 10 girls, average age: $9.3 \pm 1,13$ years, average weight: $32.9 \pm 4,95 \mathrm{~kg}$, average height: $134.4 \pm 6,76 \mathrm{~cm}$ ). 


\subsection{Measurement method}

The measurements took place at the Biomechanical Laboratory of MÁV Hospital in Szolnok using a Zebris CMS-HS ultrasound based motion analysing system (Zebris, Isny, Germany). The system and its software, WinSpine (version number: CMS-HS10 2.2, Zebris, Isny Germany) are capable of defining the shape of the spine in different postures. The head containing three ultrasound transmitters was placed behind the person examined and a triplet with three receivers was fixed on the properly palpable bone of the pelvis. Its role was to correct the motions of the pelvis during the measurement. The shape of the spine was determined by a pointer containing two microphones (Figure 1.). The system measured the propagation time of ultrasound, wherefrom the distance between the transmitter and the receiver was calculated. The positions in space (the space coordinates) of the three transmitters of the ultrasound head were known; from them, with the method of triangulation, the software calculated the space coordinates that determined the shape of the spine [8].

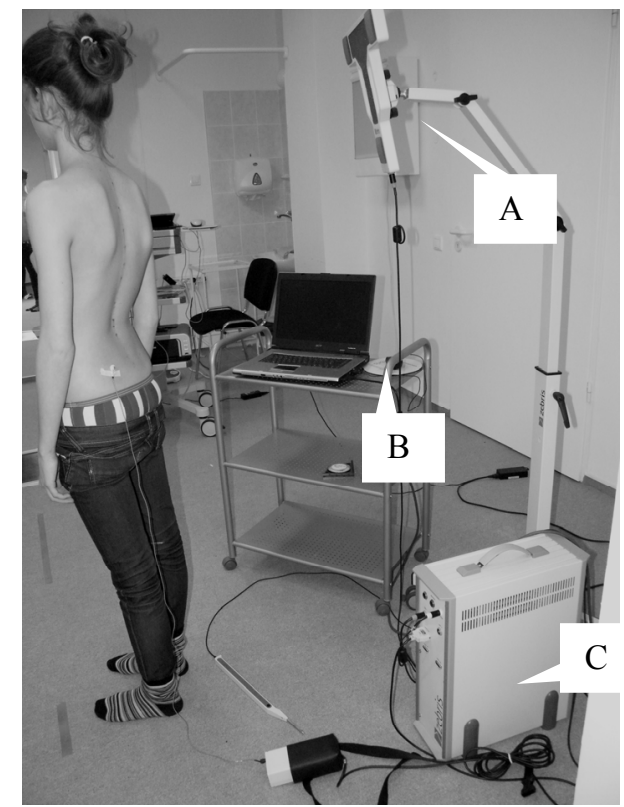

Figure 1: Measurement arrangement. Head (A) is placed behind the person examined. The triplet (B) is on the pelvis. With the pointer (C) the shape of the spine can be determined.

Measurement process (Figure 2.)

1. Positioning the child with his/her back to the measuring head.

2. The child is standing in a naturally straight position, then we call his/her attention to the correct posture, which is to let the shoulders down, press the shoulder blades back, and near to each other. The head, the pelvis, and 
the straight line which goes through the shoulders, the knees and the ankles are fitted onto an imaginary axis crossing the body centre line.

3. Designation of the global coordinate system.

4. Designation of the anatomical points necessary to define the shape of the spine: right and left shoulder, right and left angle of scapula, right and left spina iliaca posterior superior, point of Th.12-L1

5. Determining the shape of the spine in straight position three times.

6. The child stands in this position for 15 minutes.

7. After 15 minutes we determine the shape of the spine again in straight position.

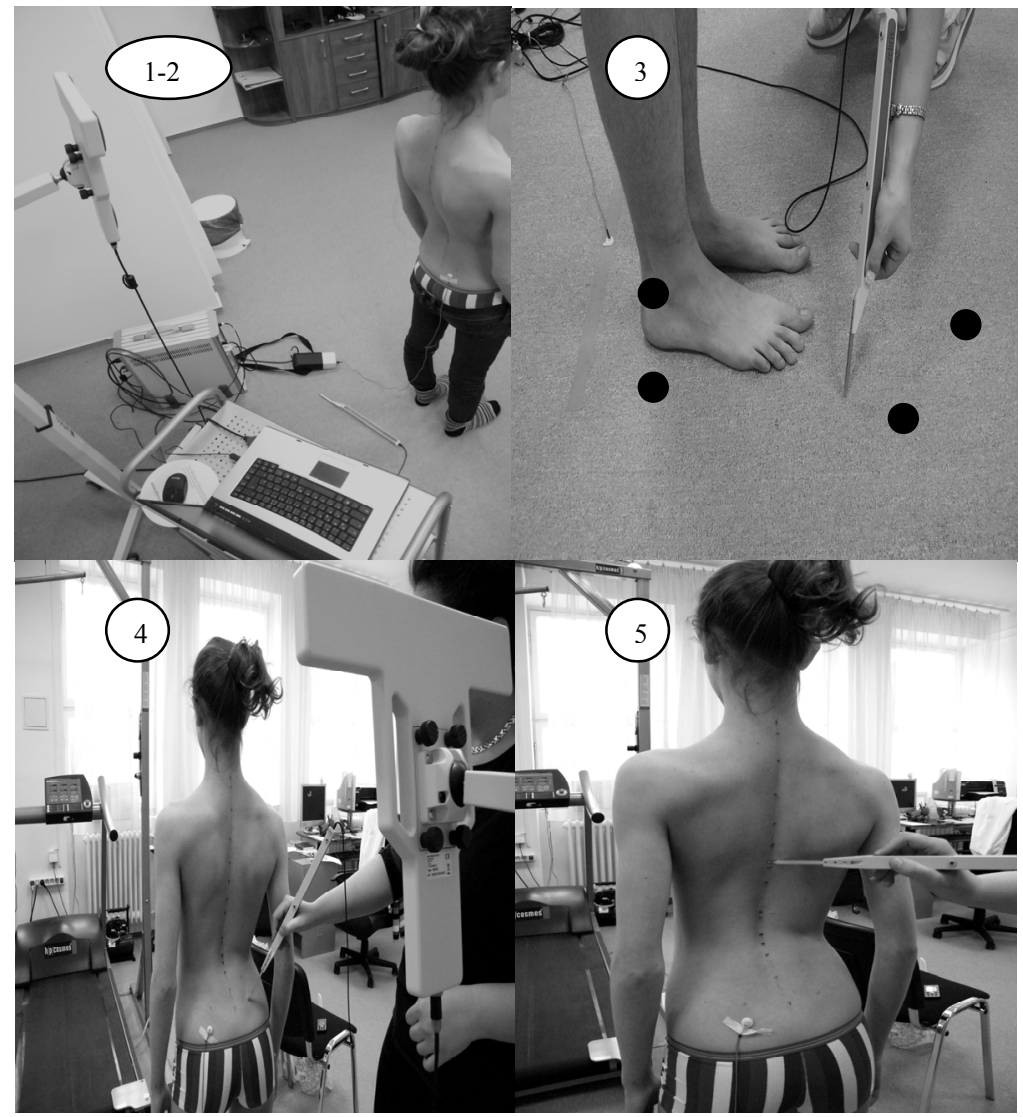

Figure 2: $\quad$ Measurement process.

With both measurements the software (WinSpine) calculates from the measurement results the angle the vertebrae form with each other, the degree of thoracal kyphosis, lumbar lordosis, scoliosis, and frontal and sagittal inclination. For the brief test-retest examination we do not use the data on vertebrae; we only 
define the degree of thoracal kyphosis, lumbar lordosis, scoliosis, and frontal and sagittal inclination.

\subsection{Statistical analysis}

We measured the effect of duration by comparing the results of the test to the results of the retest made shortly after the test. For the analysis we determined the means of the groups at both measurements, the real and the absolute scales of the differences between the two measurements, and we also made a one-sample t-test. The iteration reliability examination was supplemented by the determination of the steepness of the regression line of the two measurement results and by the determination of the Pearson correlation coefficient [16].

Table 1: $\quad$ Mean \pm standard deviation of spine curvatures (groups: healthy, bad postured, with scoliosis and with dorsum planum) at test and retest. For calculating differences we subtracted the retest values from the test values.

\begin{tabular}{|c|c|c|c|c|c|c|c|c|}
\hline & \multicolumn{4}{|c|}{ healthy } & \multicolumn{4}{|c|}{ bad posture } \\
\hline & kyphosis & lordosis & $\begin{array}{c}\text { sagittal } \\
\text { inclination }\end{array}$ & $\begin{array}{c}\text { frontal } \\
\text { inclination }\end{array}$ & kyphosis & lordosis & $\begin{array}{c}\text { sagittal } \\
\text { inclination }\end{array}$ & \begin{tabular}{|c|} 
frontal \\
inclination
\end{tabular} \\
\hline test & $41.9 \pm 7.1$ & $\begin{array}{c}32.5 \pm \\
11.2 \\
\end{array}$ & $\begin{array}{c}2.5 \pm \\
1.8 \\
\end{array}$ & \begin{tabular}{|c|}
$1.2 \pm$ \\
0.9 \\
\end{tabular} & $42.5 \pm 7.9$ & $\begin{array}{c}30.4 \pm 13 \\
2\end{array}$ & \begin{tabular}{|c|}
$3.1 \pm$ \\
2.1 \\
\end{tabular} & $\begin{array}{c}1.5 \pm \\
1.2 \\
\end{array}$ \\
\hline re-test & $41.9 \pm 8.1$ & $\begin{array}{c}32.3 \pm \\
11.8 \\
\end{array}$ & $\begin{array}{c}2.6 \pm \\
2.0 \\
\end{array}$ & $\begin{array}{c}1.3 \pm \\
1.1 \\
\end{array}$ & $42.8 \pm 7.4$ & $\begin{array}{c}29.7 \pm 14 \\
2 \\
\end{array}$ & $\begin{array}{c}3.0 \pm \\
2.6 \\
\end{array}$ & $\begin{array}{c}1.7 \pm \\
1.3 \\
\end{array}$ \\
\hline \begin{tabular}{|c|} 
real \\
difference
\end{tabular} & $\begin{array}{c}0.1 \pm \\
5.3 \\
\end{array}$ & $\begin{array}{c}0.3 \pm \\
7.7 \\
\end{array}$ & $\begin{array}{c}-0.1 \pm \\
1.9\end{array}$ & $\begin{array}{c}0.0 \pm \\
1.1\end{array}$ & $\begin{array}{c}-0.4 \pm \\
4.8\end{array}$ & $\begin{array}{c}0.9 \pm \\
8.2\end{array}$ & $\begin{array}{c}0.1 \pm \\
2.3\end{array}$ & $\begin{array}{c}-0.2 \pm \\
0.9\end{array}$ \\
\hline \begin{tabular}{|c|} 
absolute \\
difference
\end{tabular} & $\begin{array}{c}3.7 \pm \\
3.7 \\
\end{array}$ & $\begin{array}{c}4.8 \pm \\
6.1 \\
\end{array}$ & $\begin{array}{c}1.4 \pm \\
1.4 \\
\end{array}$ & $\begin{array}{c}0.8 \pm \\
0.7 \\
\end{array}$ & $\begin{array}{c}3.8 \pm \\
2.9 \\
\end{array}$ & $\begin{array}{c}5.8 \pm \\
5.9\end{array}$ & $\begin{array}{c}1.6 \pm \\
1.7 \\
\end{array}$ & $\begin{array}{c}0.7 \pm \\
0.6\end{array}$ \\
\hline & \multicolumn{4}{|c|}{ dorsum planum } & \multicolumn{4}{|c|}{ scoliosis } \\
\hline & kyphosis & lordosis & $\begin{array}{c}\text { sagittal } \\
\text { inclination }\end{array}$ & $\begin{array}{c}\text { frontal } \\
\text { inclination }\end{array}$ & kyphosis & lordosis & $\begin{array}{c}\text { sagittal } \\
\text { inclination }\end{array}$ & $\begin{array}{c}\text { frontal } \\
\text { inclination }\end{array}$ \\
\hline test & $35.8 \pm 6.6$ & $\begin{array}{c}16.0 \pm \\
10.7\end{array}$ & $\begin{array}{c}3.4 \pm \\
2.6\end{array}$ & $\begin{array}{c}1.2 \pm \\
1.0\end{array}$ & $37.1 \pm 6.9$ & $\begin{array}{c}30.7 \pm \\
11.2\end{array}$ & $\begin{array}{c}3.4 \pm \\
2.0\end{array}$ & $\begin{array}{c}1.3 \pm \\
1.1 \\
\end{array}$ \\
\hline re-test & $38.5 \pm 7.2$ & $\begin{array}{c}23.4 \pm \\
14.1\end{array}$ & $\begin{array}{c}2.3 \pm \\
2.3\end{array}$ & $\begin{array}{l}1.1 \pm \\
0.8\end{array}$ & $38.6 \pm 6.3$ & $\begin{array}{c}31.1 \pm \\
13.4\end{array}$ & $\begin{array}{c}2.5 \pm \\
1.9\end{array}$ & $\begin{array}{l}1.5 \pm \\
1.0\end{array}$ \\
\hline \begin{tabular}{|c|} 
real \\
difference
\end{tabular} & $\begin{array}{c}-2.7 \pm \\
1.5\end{array}$ & $\begin{array}{c}-7.4 \pm \\
5.6\end{array}$ & $\begin{array}{c}1.1 \pm \\
1.1\end{array}$ & $\begin{array}{c}0.1 \pm \\
1.1\end{array}$ & $\begin{array}{c}-1.5 \pm \\
4.4\end{array}$ & $\begin{array}{c}-0.4 \pm \\
6.5\end{array}$ & $\begin{array}{c}0.9 \pm \\
1.1\end{array}$ & $\begin{array}{c}-0.2 \pm \\
1.2\end{array}$ \\
\hline \begin{tabular}{|c|} 
absolute \\
difference
\end{tabular} & $\begin{array}{c}2.7 \pm \\
1.5\end{array}$ & $\begin{array}{c}7.4 \pm \\
5.6\end{array}$ & $\begin{array}{c}1.2 \pm \\
1.0\end{array}$ & $\begin{array}{c}0.8 \pm \\
0.7\end{array}$ & $\begin{array}{c}3.4 \pm \\
3.0\end{array}$ & $\begin{array}{c}5.1 \pm \\
3.9\end{array}$ & $\begin{array}{c}1.1 \pm \\
0.9\end{array}$ & $\begin{array}{c}1.0 \pm \\
0.6\end{array}$ \\
\hline
\end{tabular}

\section{Results}

Table 1 shows the mean and standard deviation figures calculated from the measurement results of the test and the retest performed 15 minutes later. The real and absolute scale of the error can be seen. The results indicate that the mean values of the errors are smaller than the standard deviations of the measurement 
results. The biggest real and absolute errors were yielded at the lordosis values of children with dorsum planum (7.4 \pm 5.6 degrees).

With each group we defined the significance of differences between measurement results (p) (Table 2.) and we can say that no significant differences were found. The next step of statistical analysis was to calculate the correlation coefficient (r) and the steepness of the straight line fitted on the data (m) (Table 2.).

Table 2: Correlation coefficient between the test and retest values (r), the regression line $(\mathrm{m})$ and the significance values between the groups (p).

\begin{tabular}{|c|c|c|c|c|c|c|c|c|}
\hline & \multicolumn{5}{|c|}{ healthy } & \multicolumn{4}{c|}{ bad posture } \\
\hline & kyphosis & lordosis & $\begin{array}{c}\text { sagittal } \\
\text { inclination }\end{array}$ & $\begin{array}{c}\text { frontal } \\
\text { inclination }\end{array}$ & kyphosis & lordosis & $\begin{array}{c}\text { sagittal } \\
\text { inclination }\end{array}$ & $\begin{array}{c}\text { frontal } \\
\text { inclination }\end{array}$ \\
\hline$r$ & 0.77 & 0.78 & 0.48 & 0.46 & 0.84 & 0.82 & 0.54 & 0.73 \\
\hline$m$ & 0.88 & 0.82 & 0.51 & 0.54 & 0.76 & 0.88 & 0.69 & 0.80 \\
\hline$p$ & 0.462865 & 0.450093 & 0.358221 & 0.373164 & 0.400377 & 0.361592 & 0.440134 & 0.260105 \\
\hline & \multicolumn{5}{|c|}{ dorsum planum } & \multicolumn{5}{c|}{ scoliosis } \\
\hline & kyphosis & lordosis & $\begin{array}{c}\text { sagittal } \\
\text { inclination }\end{array}$ & $\begin{array}{c}\text { frontal } \\
\text { inclination }\end{array}$ & kyphosis & lordosis & $\begin{array}{c}\text { sagittal } \\
\text { inclination }\end{array}$ & $\begin{array}{c}\text { frontal } \\
\text { inclination }\end{array}$ \\
\hline$r$ & 0.98 & 0.93 & 0.90 & 0.18 & 0.78 & 0.88 & 0.84 & 0.36 \\
\hline$m$ & 1.07 & 1.23 & 0.80 & 0.14 & 0.71 & 1.05 & 0.80 & 0.33 \\
\hline$p$ & 0.257076 & 0.16553 & 0.226076 & 0.437279 & 0.242599 & 0.456956 & 0.084477 & 0.280707 \\
\hline
\end{tabular}

The results indicate that the lordosis and kyphosis values show a good accord among the groups, because the correlation coefficient is high (range: 0.98-0.77), which is also proved by the steepness of the regression line values close to one (range: 0.82-1.23).

The correlation between results at sagittal and frontal inclination is only average (healthy, bad postured) or weak at frontal inclination (flat back, scoliosis) (0.18-0.36). These data are also verified by the steepness because its values are far from one $(0.14-0.33)$.

\section{Discussion}

Previous studies examined the reliability of the measurement method, which means that the tests were repeated after a longer interval (1-3 weeks) [13]. The novelty of our examination was that we examined the effect of the time span of the measurement. The question of the research was whether the results of the test correlate with the results of the measurement 15 minutes later. Results indicate that in terms of the degree of kyphosis and lordosis the correlation between the two results is good, which is confirmed by the steepness value of the regression line which is close to one. These results are similar to those derived from the examination of the reliability of the measurement repeated after a long time (1-3 weeks), when adults were examined, but contradict Geldhof's statements, 
who examined the children again one week later and got low correlation coefficients. The cause of the contradiction could be that Geldhof and his colleagues measured the natural posture and did not call the children's attention to correct their posture. The reason for the medium or low correlation between the two values determining the position of the median can be that the position of the median and the centre of gravity changes continuously, which is proved by stability tests based on the examination of the position of the centre of gravity. It is known that in children the movement of the weight centre is much bigger than in adults and, on the other hand, the decline of attention is first shown by inclination.

\section{Conclusion}

The ultrasound-based motion analyzing system is commonly used for determining the shape of the spine in adults, but it is rarely mentioned in medical literature in connection with children's spine examinations. The advantage of the system is that there is no X-ray radiation; it is quick and gives graphic and numerical information about the temporary status of the spine. For daily use it is very important that the positions examined must be standardized and the time of the examination must not influence the results. The statistical analysis of the measurement results of the test-retest indicates that at straight position, when the degree of kyphosis and lordosis is calculated, the time span of the measurement does not influence measurement results. As regards the measurement of inclination, the correct positioning of the posture examined must be checked before each and every measurement.

\section{Acknowledgements}

This work is connected to the scientific program of the "Development of qualityoriented and harmonized $\mathrm{R}+\mathrm{D}+\mathrm{I}$ strategy and functional model at BME" project. This project is supported partly by the New Hungary Development Plan (Project ID: TÁMOP-4.2.1/B-09/1/KMR-2010-0002). This work was supported by the Hungarian Scientific Fund T075018.

\section{References}

[1] Geldhof E., Cardon G., Bourdeaudhuij I. D., \& Clercq. D. D., Back posture education in elementary schoolchildren: a 2-year follow-up study. Eur Spine J. 16, pp.841-850, 2007.

[2] Cardon G., \& Balagué F., Low back pain prevention's effects in schoolchildren. What is evidence? Eur Spine J. 13, pp. 663-679, 2004.

[3] Kratenová J., Zejglicová K., Maly M., \& Filipová V., Prevalence and risk factors of poor posture in school children in the Czech Republic. Journal of School Health. 77(3), pp.131-137, 2007 
[4] Jones M.A., Stratton G., Reilly T., \& Unnithan V.B., Biological risk indicators for recurrent non-specific low back pain in adolescent. $\mathrm{Br}$ J Sports Med 39, pp.137-140, 2005.

[5] Jones M.A., Stratton G., Reilly T., \& Unnithan V.B., A school-based survey of recurrent non-specific low back pain prevalence and consequences in children. Health Educ Res 19, pp.284-289, 2004.

[6] Salminen J.J., Erkintalo M., Laine M., \& Pentti J., Low back Pain in the young a prospective 3 year follow-up-study of subjects without low-back-pain. Spine 20, pp.2101-2107, 1995.

[7] Brattberg G. Do pain problems in young school children persist into early adulthood? A 13-year follow-up. Eur J Pain 8, pp.187-199, 2004

[8] Zsidai A., \& Kocsis L., Ultrasound-based spinal column examination systems. Facta Universitatis Physical Education and Sport 1(8), pp.1-12, 2001.

[9] Post R.B., \& Leferink V.J.M., Spinal Mobility: sagittal range of motion measured with the Spinal Mouse, a new non-invasive device. Arch Orthop Trauma Surg 124, pp.187-192, 2004

[10] Viola S., Kocsis L., Szőke Gy., Körmendi Z., \& Zsidai A., Kinesiological examinations and cutaneous EMG with integrated 3D UH system in adolescent idiopathic scoliosis (type:King1-13) Orv. Hetilap 147, pp.2367-75, 2006.

[11] Zsidai A. \& Kocsis L., Ultrasound measuring diagnostic and muscle activity measuring system for spinal analysis, Technology and Health Care 14, pp.243-250, 2006.

[12] Asamoah V, Melleriwicz H, Venus J, \& Klöckner C., Measuring the surface of the back. Value in diagnosis of spinal diseases. 29(6), pp.4804892000.

[13] Geldhof, E., Cardon, G., Bourdeaudhuij I. D., Danneels L., Coorevits P., Vanderstraeten G., \& Clarcq D.D., Effects of back posture education on elementary schoolchildren's back function. Eur Spine J, 16, pp.829-839, 2007.

[14] Malmström E.M., Karlberg M., Melander A., \& Magnusson M., Zebris Versus Myrin: A Comparative Study between a Three-Dimensional Ultrasound Movement Analysis and an Inclinometer/Compass Method; Spine 28, pp.E 433-E440, 2003

[15] Mannion A. F., Knecht K., Balaban G., Dvorak J., \& Grob D, A new skin-surface device for measuring the curvature and global and segmental range of motion of the spine: reliability of measurements and comparison with data review from the literature. Eur Spine J. 13, pp.122-136, 2004.

[16] Bland MJ., \& Altman D.G., Statistical methods for assessing agreement between two methods of clinical measurement. The Lancet, 1, pp.307-310, 1986. 